Angela Paula Simonelli ${ }^{1}$

João Alberto Camarotto²

Ecléa Spiridião Bravo ${ }^{3}$

Rodolfo Andrade de Gouveia Vilela ${ }^{4}$

\section{Proposta de articulação entre abordagens metodo- lógicas para melhoria do processo de reabilitação profissional}

\author{
Proposing an articulation between methodologies to improve \\ occupational rehabilitation process
}

\author{
1 Terapeuta Ocupacional do Centro de \\ Referência em Saúde do Trabalhador \\ - Cerest-Piracicaba, SP. \\ 2 Docente da Universidade Federal de \\ São Carlos (UFSCar), Departamento de \\ Engenharia da Produção, São Carlos, SP. \\ ${ }^{3}$ Médica do Cerest-Piracicaba e res- \\ ponsável técnica do Programa Reabilita \\ do Instituto Nacional do Seguro Social \\ (INSS) de Piracicaba, SP. \\ ${ }^{4}$ Docente da Faculdade de Saúde Públi- \\ ca da Universidade de São Paulo (USP). \\ Contato: \\ Angela Paula Simonelli \\ Rua Viriato Fernandes Nunes, 70. Apto. \\ 09. Jardim Santa Paula, São Carlos - SP \\ CEP: 13564-070 \\ E-mail:
}

angela@dep.ufscar.br

\section{Resumo}

Este artigo discute as limitações do atual modelo de reinserção do programa de reabilitação profissional do INSS para o retorno do trabalhador afastado por acidente ou doença ocupacional. Estas limitações são discutidas em relação à avaliação parcial da incapacidade do trabalhador e à não consideração estruturada da relação homem-trabalho por ocasião do retorno do trabalhador ao seu local de trabalho. Propõe-se um modelo que utiliza a Classificação Internacional de Funcionalidade, Incapacidade e Saúde (CIF) como referência para os profissionais selecionarem avaliações de caráter biopsicossocial para classificação das potencialidades do trabalhador reabilitado e a Análise Ergonômica do Trabalho (AET) como abordagem para a adaptação dos locais de trabalho. O modelo da CIF considera que a incapacidade não é um atributo da pessoa, mas sim um conjunto de condições que resulta da interação pessoa-meio. A AET pressupõe a compreensão do trabalho nas suas dimensões física, cognitiva e organizacional, cuja análise é centrada na atividade real. Resulta desta proposta uma maior aproximação entre as exigências do trabalho e as potencialidades do trabalhador numa visão social do problema da reinserção.

Palavras-chave: ergonomia; reabilitação; reinserção no trabalho; incapacidade.

\begin{abstract}
This article discusses the limitations of the current work reinsertion pattern adopted by the National Social Security Institute (INSS) in its occupational rehabilitation program aimed at preparing workers to return to work after being on leave due to occupational illness or accident. These limitations are discussed regarding inadequate assessment of worker's disability and established disregard for the man-work relationship at the time workers return to their workplaces. We propose a model, which uses the International Classification of Functionality, Disability and Health (ICF) as a reference to select biopsychosocial criterion to assess the rehabilitated workers' potentials, and Ergonomic Work Analysis (EWA) as an approach to adapt workplaces for the rehabilitated workers' return. ICF considers that disability is not an individual characteristic, but a set of conditions resulting from the person-environment interaction. EWA presumes that work is understood in its physical, cognitive, and organizational dimensions, and analyzed focusing on real activity. The proposal of this article is to narrow the gap between job demands and workers' potentials, viewing the reinsertion problem from a social standpoint.
\end{abstract}

Keywords: ergonomics; rehabilitation; work reinsertion; disability. 


\section{Introdução}

Dados da Organização Mundial de Saúde (OMS) apontam as lesões traumáticas como o maior problema de saúde pública da atualidade, originadas em acidentes de trânsito, acidentes de trabalho e acidentes gerados pela violência (TAKAHASHI, 2006). Segundo o censo demográfico de 2000 do IBGE, há no Brasil 24.800.256 pessoas com pelo menos um tipo de incapacidade.

Segundo Moon e Geicker (1998, apud TAKAHASHI, 2006), a política pública sobre reabilitação profissional tem o papel de regulação econômica dos sistemas com a finalidade de reduzir o tempo de benefícios por incapacidade e de intervenção para a redução e a superação das desvantagens produzidas pelas incapacidades.

No Brasil, a reabilitação profissional do Instituto Nacional do Seguro Social (INSS) é o único serviço oficial com essa finalidade voltado para os trabalhadores de todas as categorias profissionais que contribuem com a Previdência Social e que estão em percepção de benefício por incapacidade, e os seus dependentes maiores de 16 anos com deficiência. Também inclui os aposentados por invalidez, espontaneamente, ou quando da revisão do benefício, os dependentes pensionistas inválidos e as pessoas com deficiência sem vínculo com a Previdência, mediante convênio de cooperação técnico-financeira com instituições ou empresas (Lei no 8213/91).

Apoiado num arcabouço legal que vai desde as leis até os memorandos internos, esse serviço foi alvo de intensas mudanças na década de 1990.

Ao sair de uma concepção sociopolítica da incapacidade para uma visão biomédica das lesões e suas causas, restringindo o conceito de incapacidade apenas para seus aspectos físicos, contextualizado com as medidas neoliberais orientadoras dessas mudanças, o programa de reabilitação profissional do INSS, agora denominado Reabilita, adota diretrizes que caminham em sentido oposto àquelas definidas por Moon e Greick (TAKAHASHI, 2006).

Autores que defendem uma concepção sociopolítica da incapacidade definem reabilitação profissional como um processo terapêutico e de profissionalização de forma integral, fortalecendo o indivíduo para superar as dificuldades decorrentes de sua incapacidade. Além da estabilização física, da ampliação da força e dos movimentos, procura atuar na estabilização psicossocial, na integração das relações sociais, cotidianas e de trabalho, através de uma identidade ressignificada. Países industrializados e desenvolvidos como Austrália, Nova Zelândia, Alemanha e EUA incorporam serviços de colocação no emprego como parte integrante de um sistema nacional de assistência às pessoas com incapacidade e adotam uma legislação com enfoque na antidiscriminação (SEYFRIED, 1998, apud TAKAHASHI, 2006).

No Brasil, o programa Reabilita não se responsabiliza pela reabilitação física do trabalhador. Esta etapa é atribuída ao Serviço Único de Saúde (SUS). Assim, quando encaminhado para o Reabilita, o trabalhador deve estar com sua lesão estável. A reabilitação profissional se resume no encaminhamento do trabalhador de volta à empresa de vínculo para função compatível e/ou curso de requalificação profissional ou de elevação de escolaridade, quando a empresa não oferece função ou quando o trabalhador está desempregado. Essa dicotomia impede uma visão integrada do processo de reabilitação como proposto pela concepção sociopolítica da incapacidade. Os aspectos psicossociais deste processo ficam perdidos, sendo considerados apenas os aspectos biomédicos. Além disso, no Brasil, não há obrigatoriedade da colocação no emprego pelo programa público de reabilitação profissional.

Foram requeridos, no mês de junho de 2006, 604.635 benefícios por incapacidade no Brasil, segundo dados do Sistema Unificado de Informação de Benefícios (SUIBE), do INSS. Destes, 373.321 foram concedidos como auxílio-doença previdenciário, sendo 10.795 aposentados por invalidez e 2.541 concedidos como auxílio-acidente do trabalho, sendo 256 aposentadorias por invalidez decorrentes de acidente do trabalho.

Segundo o Boletim Estatístico de Reabilitação Profissional (BERP) do INSS, foram registrados, no mesmo período, 40.849 casos no Reabilita e, destes, apenas $2.670(6,4 \%)$ retornaram ao trabalho após cumprirem o programa de reabilitação profissional.

Levantamento realizado pela Diretoria de Saúde e Segurança Ocupacional da Secretaria de Políticas de Previdência do Ministério da Previdência Social mostrou que, por ano, o INSS paga R $\$ 10,5$ bilhões em benefícios devido a acidentes e doenças do trabalho e aposentadorias especiais decorrentes das condições ambientais do trabalho. Além dos valores pagos, as consequências das más condições nos ambientes de trabalho para aqueles que estão expostos são imensuráveis.

No âmbito das políticas públicas, necessita-se de ações que alterem esse cenário, em especial a necessidade da superação da fragmentação institucional entre áreas afins como Trabalho, Saúde e Previdência, que deem conta de uma política de Estado que consiga uma intervenção preventiva nos determinantes dos agravos à saúde decorrentes de processos patológicos de trabalho. Não se pode admitir como natural que o Estado Brasileiro assista passivamente a ocorrência evitável de epidemias de lesões e sequelas de trabalhadores.

As parcerias interinstitucionais exigem troca e transparência de dados e informações. Existe uma grande dificuldade do INSS na disponibilidade de dados para fins de ações conjuntas, principalmente aqueles de importância estratégica para as ações em saúde do trabalhador, como, por exemplo, o número de trabalhadores afastados por empresa em decorrência de agravos à saúde resultantes das atividades laborais. Essa atitude institucional tem sido motivo de tensões e conflitos entre os parceiros, uma vez que só favorece a manutenção do status quo e contraria o Art. 39, parágrafo 8o da Lei no 8.080/1990 (Lei Orgânica de Saúde) e as Diretrizes da Política Nacional 
de Segurança e Saúde dos Trabalhadores, que têm entre suas estratégias:

Compatibilizar os sistemas e bases de dados a serem partilhados pelos Ministérios do Trabalho, Previdência Social, Meio Ambiente e Saúde;[...] Compatibilizar os instrumentos de coleta de dados e fluxos de informações. (BRASIL, 2005)

Pressionados pelo movimento sindical e por pesquisadores das questões relacionadas ao mundo do trabalho, encontra-se em discussão, no Ministério da Previdência Social e no INSS, um modelo de revitalização do Reabilita que permita a integração das várias instituições que fazem interface com a saúde do trabalhador: saúde, previdência e trabalho e emprego.

A reabilitação dos trabalhadores acidentados e daqueles que possuem doenças profissionais passa necessariamente por mudanças efetivas na organização dos setores de trabalho e nos critérios de incapacidade. A utilização da Classificação Internacional de Funcionalidade, Incapacidade e Saúde (CIF) como referencial para a avaliação dos trabalhadores e da AET na avaliação dos processos de trabalho planejada através do estudo da incidência do número de casos em reabilitação profissional por empresa, incluindo a participação do Ministério do Trabalho e Emprego de modo a garantir a intervenção no processo produtivo e não adoecer mais trabalhadores, seria uma estratégia eficaz na redução dos danos e, por conseguinte, dos custos previdenciários e da saúde.

Assim, este artigo objetiva propor uma articulação metodológica que hoje faz falta na área de readaptação.

\section{A perícia médica do INSS e a reabilitação profissional}

O conceito de incapacidade é um elemento central no fundamento e na lógica de organização dos sistemas de previdência social (MOON; GEICKER, 1988, apud TAKAHASHI, 2006).

No Brasil, o Decreto no 3.298/99, que dispõe sobre a política nacional de integração da pessoa com deficiência e consolida as normas de proteção definidas pela Lei no 7.853/89, define dois conceitos importantes para a implantação de programas de reabilitação profissional: 1) deficiência: toda perda ou anormalidade de uma estrutura ou função psicológica, fisiológica ou anatômica que gere incapacidade para o desempenho da atividade, dentro do padrão considerado normal para o ser humano; 2) incapacidade: redução efetiva e acentuada da capacidade de integração social, com necessidade de equipamentos, adaptações, meios ou recursos especiais para que a pessoa com deficiência possa receber ou transmitir informações necessárias ao seu bem-estar e ao desempenho de atividade a ser exercida.

Embora esses conceitos sejam amplos, o perito médico do INSS responsável pelo encaminhamento do trabalhador ao programa de reabilitação profissional e pela avaliação do seu potencial laborativo depara-se com critérios restritivos para esta avaliação nas normas previdenciárias.

Ao entender a incapacidade como a impossibilidade do trabalhador "de atingir a média de rendimento/produção alcançada em condições normais pelos trabalhadores da categoria do examinado" (TREZUB, 2006), não fica claro o que são condições normais? Quais as exigências reais das atividades laborativas do examinado? Quais os parâmetros epidemiológicos considerados para avaliar o rendimento/produção da categoria do examinado?

E ainda: “o indivíduo é considerado capaz para exercer uma determinada atividade ou ocupação quando reúne as condições morfopsicofisiológicas compatíveis com o seu pleno desempenho" (TREZUB, 2006), mas, qual é o desempenho?

A concepção sociopolítica da incapacidade, apoiada nos conhecimentos técnicos e científicos, mostra que a incapacidade aumenta na medida em que o ambiente social falha em se ajustar às necessidades das pessoas incapacitadas (TAKAHASHI, 2006). Assim, ser incapaz/capaz requer um referencial: incapaz/capaz para quê? Em que condições?

A classificação de abrangência de incapacidade adotada nos manuais da perícia médica do INSS como uniprofissional, multiprofissional e omniprofissional (incapacidade para toda e qualquer atividade justifica a aposentadoria por invalidez) não se enquadra nos pressupostos sociopolíticos da incapacidade, pois considera apenas os determinantes físicos da incapacidade.

Distante dessas reflexões de forma abstrata e solitária ou, quando muito, com base nas tarefas prescritas fornecidas pelo perfil profissiográfico elaborado pelas empresas, o perito médico do INSS decide o futuro profissional e/ou a concessão do benefício ao trabalhador.

Quando encaminhado ao Reabilita, o trabalhador deve obrigatoriamente cumprir o programa de reabilitação profissional, que consiste na análise conjunta, de médicos peritos e orientadores profissionais, das condições socioeconômicas, do nível de escolaridade e do potencial laborativo do trabalhador e na solicitação à empresa de função compatível com as restrições observadas. O certificado de reabilitado é concedido ao trabalhador quando ele retorna à empresa em uma nova função ou na mesma função com restrições, após treinamento, ou quando a empresa recusa o retorno, porém, o trabalhador se qualifica para uma nova função através de cursos de capacitação ou profissionalizantes.

Com o certificado de reabilitado, o trabalhador pode preencher as vagas criadas pela Lei $n^{0}$ 8.213/91 (Lei de Cotas) nas empresas. Uma vez certificado pelo INSS, o Ministério do Trabalho e Emprego não questiona a compatibilidade ou não da função oferecida com as restrições do trabalhador, o que dá ao programa de reabilitação profissional do INSS uma grande responsabilidade ao concluir uma certificação. 
É previsto na legislação previdenciária a visita da equipe do programa de reabilitação ao posto de trabalho, mas as avaliações são pontuais e restritas aos casos de resistência sistemática de retorno ao trabalho. Além disso, existe uma fragilidade da equipe em negociar novos postos de trabalho com as empresas devido ao desconhecimento dos riscos existentes no ambiente, no processo de trabalho e nas relações de trabalho, resultando em baixa fixação dos trabalhadores nas novas funções. A falta de articulação com as empresas, muitas vezes, provoca a demissão do trabalhador ou o retorno para a perícia médica após algum tempo, tornando o processo de reabilitação profissional ineficaz.

A reabilitação profissional é uma atribuição do Ministério da Previdência Social, mas só ela não garantirá as melhorias que se fazem necessárias para o retorno ao trabalho dos seus segurados na mesma função ou não. A eficácia e a efetividade da reabilitação profissional dependem de políticas econômicas que privilegiem não apenas o crescimento econômico, mas a vida e a saúde do trabalhador, de políticas preventivas nos ambientes de trabalho, da assistência em saúde para procedimentos diagnósticos, terapêuticos e de reabilitação adequados, e de intervenções, nas atividades e nas relações de trabalho, das empresas com os reabilitados (TAKAHASHI, 2006).

\section{Abordagens sobre o conceito de inca- pacidade}

Em contraposição às abordagens biomédicas que orientam as diretrizes do programa de reabilitação profissional do INSS, tem sido desenvolvida uma corrente político-teórica iniciada no Reino Unido desde a década de 1960: o modelo social da incapacidade (OLIVER, 1990). Segundo este autor, a ideia básica do modelo social é a de que a incapacidade não deve ser entendida como um problema individual, mas como uma questão eminentemente social.

O ponto de partida teórico do modelo social é que a incapacidade é uma experiência resultante da interação entre características corporais do indivíduo e as condições da sociedade em que ele vive, isto é, da combinação de limitações impostas pelo corpo com algum tipo de perda ou redução de funcionalidade (lesão) a uma organização social pouco sensível à diversidade corporal (OLIVER, 1990).

O modelo biomédico vê a incapacidade como um atributo da pessoa, diretamente causada por doença, trauma ou por outra condição de saúde, que requer cuidado médico oferecido na forma de tratamento individual por profissionais. A incapacidade, neste modelo, requer tratamento médico ou outro tratamento ou intervenção para "corrigir"o problema na estrutu- ra do corpo da pessoa (ORGANIZAÇÃO MUNDIAL DA SAÚDE, 2002).

O modelo social de incapacidade, por outro lado, vê a incapacidade como um problema socialmente criado e não totalmente como um atributo de um indivíduo. No modelo social, a incapacidade demanda uma resposta política, uma vez que o problema é criado por um ambiente não acomodatório, trazido por atitudes e outras características do ambiente social (ORGANIZAÇÃO MUNDIAL DA SAÚDE, 2002).

Ao revisar a contribuição das diferentes teorias para os estudos da incapacidade, Oliver (1998) considera que o positivismo tem dominado os estudos nessa área com pesquisas, geralmente, que buscam, através de métodos estruturados, conhecer variáveis objetivas, mas desprezando a subjetividade dos que vivem a experiência da deficiência ou da incapacidade. Critica a influência da teoria funcionalista nos estudos e as intervenções do modelo biomédico, que visaria curar e manter dentro do funcionamento "normal" os indivíduos e a sociedade, confundindo incapacidade e deficiência com doenças, assim como tratando essas pessoas como um grupo homogêneo.

O autor opina que, embora poucos, os estudos específicos sobre a incapacidade e a deficiência têm tido o mérito de relativizar o conceito de corpo saudável, permitindo que se veja que apresentar uma incapacidade não significa, necessariamente, não ter saúde.

Verbrugge (1994) coloca que a incapacidade é um gap entre a capacidade pessoal e a demanda das tarefas e que, para reduzi-la, pode-se intervir de duas maneiras: incrementando a capacidade das pessoas, seguindo o modelo biomédico mais frequentemente utilizado, ou ajustando a demanda das tarefas, neste caso seguindo os pressupostos do modelo social da deficiência e da análise da atividade.

Segundo a Organização Mundial da Saúde (2002), ambos os modelos são válidos, porém, a incapacidade é um fenômeno complexo que é tanto um problema no corpo da pessoa, como também um fenômeno complexo e primariamente social. A incapacidade é sempre uma interação entre os atributos da pessoa e os atributos do contexto geral em que esta vive, mas alguns aspectos da incapacidade são quase inteiramente internos à pessoa, enquanto alguns outros aspectos são quase inteiramente externos. Em outras palavras, ambas as respostas médica e social são apropriadas aos problemas associados à incapacidade e não podemos rejeitar totalmente qualquer um dos tipos de intervenção.

Um modelo mais adequado de incapacidade, em resumo, é aquele que sintetiza os dois modelos (biomédico e social) sem cometer o erro de reduzir a noção complexa e total de incapacidade a apenas um dos seus aspectos. 


\section{Classificação Internacional de Funcio- nalidade, Incapacidade e Saúde (CIF)}

A CIF é baseada na integração dos modelos biomédico, psicológico e social. A CIF fornece, por esta síntese, uma visão coerente de diferentes perspectivas da saúde: biológica, individual e social. A funcionalidade e a incapacidade de uma pessoa são concebidas como uma interação dinâmica entre os estados de saúde (doenças, perturbações, lesões etc.) e os fatores contextuais (fatores ambientais e pessoais) (BUCHALLA, 2001). A incapacidade não é um atributo da pessoa, mas sim um conjunto complexo de condições que resulta da interação pessoa-meio.

O uso da CIF já está previsto na legislação previdenciária para a concessão do Benefício de Prestação Continuada (BPC) através do decreto que regulamenta a Lei Orgânica da Assistência Social (LOAS). Está em discussão, no plano de revitalização do Reabilita, a implantação da CIF para subsidiar os profissionais na avaliação da incapacidade dos trabalhadores em programa de reabilitação profissional.

O termo "incapacidade" introduzido pela CIF difere do termo "utilizado" pela ICIDH, classificação da Organização Mundial de Saúde (OMS) anterior à CIF. Enquanto na ICIDH, incapacidade era definida como qualquer restrição ou falta (resultante de uma deficiência) da capacidade para realizar uma atividade dentro dos moldes e limites considerados normais para um ser humano, com a CIF, incapacidade (disability) não é definida como consequência de uma deficiência (impairment, deficiency), mas sim como o resultado da interação da pessoa com o meio ambiente.

O modelo da CIF substitui o enfoque negativo da deficiência e da incapacidade por uma perspectiva po- sitiva, considerando as atividades que um indivíduo que apresenta alterações de função e/ou da estrutura do corpo pode desempenhar, assim como sua participação social. A funcionalidade e a incapacidade dos indivíduos são determinadas pelo contexto ambiental onde as pessoas vivem. As classificações consistem em uma análise de relato clínico e histórico ocupacional, além de avaliações clínicas da estrutura do corpo, seguindo a proposta da classificação da OMS.

Segundo o Quadro 1, as funções do corpo são definidas como as funções fisiológicas e psicológicas dos sistemas do corpo. As estruturas são definidas como as partes anatômicas do corpo, como os órgãos e seus componentes. A atividade e a participação (A \& P) descrevem como o indivíduo exerce suas atividades diárias e se engaja na vida social, considerando as funções e as estruturas do seu corpo. O conteúdo desses componentes (A \& P) é organizado desde as simples tarefas e ações até as áreas mais complexas da vida, sendo incluídos itens referentes: à aprendizagem e à aplicação do conhecimento; a tarefas e demandas gerais; à comunicação, à mobilidade, aos cuidados pessoais, às atividades e às situações da vida doméstica; a relações e interações interpessoais; à educação e ao trabalho; à autosuficiência econômica; à vida comunitária (BUCHALLA, op. Cit.).

Ainda, no Quadro 1, os fatores ambientais compreendem os fatores externos do meio ambiente onde a pessoa vive e podem caracterizar-se como barreiras ou facilitadores à execução de atividades e ao envolvimento das pessoas numa situação da vida social. Esse componente inclui itens referentes a produtos e tecnologia; ambiente natural como clima, luz, som; apoios e relacionamentos; atitudes individuais e sociais; normas e ideologias; serviços, sistemas e políticas de previdência social, saúde, educação, trabalho e emprego, transportes, dentre outros (BUCHALLA, op. Cit.).

Quadro 1 Conceituações e terminologias dos componentes relatados na CIF

\begin{tabular}{|c|c|c|c|c|}
\hline Componente & $\begin{array}{l}\text { Estruturas do corpo } \\
\text { Funções do corpo }\end{array}$ & Atividade & Participação & Fatores ambientais \\
\hline Definição & $\begin{array}{l}\text { Funções do corpo são as funções } \\
\text { fisiológicas dos sistemas do corpo } \\
\text { (incluindo as funções mentais). } \\
\text { Estruturas do corpo são as partes } \\
\text { anatômicas do corpo. }\end{array}$ & $\begin{array}{l}\text { Atividade é a execução de } \\
\text { tarefas realizadas no dia a } \\
\text { dia de um indivíduo. }\end{array}$ & $\begin{array}{l}\text { Participação é o } \\
\text { envolvimento numa } \\
\text { situação da vida } \\
\text { social }\end{array}$ & $\begin{array}{l}\text { Compreende os } \\
\text { fatores exter- } \\
\text { nos do meio } \\
\text { ambiente onde a } \\
\text { pessoa vive }\end{array}$ \\
\hline Aspecto Positivo & Integralidade funcional e estrutural & Atividade & Participação & Facilitadores \\
\hline \multicolumn{5}{|l|}{ Funcionalidade } \\
\hline Aspecto Negativo & Deficiência & Limitação da atividade & $\begin{array}{l}\text { Restrição da partici- } \\
\text { pação }\end{array}$ & $\begin{array}{l}\text { Barreiras/obs- } \\
\text { táculos }\end{array}$ \\
\hline
\end{tabular}

Fonte: Adaptado de: (1) WHO. Towards a Common Language for Functioning, Disability and Health - ICF. Geneva, 2002 e (2) OMS. Classificação Internacional de Funcionalidade, Incapacidade e Saúde. São Paulo: Edusp, 2003. 
As limitações de atividade são as dificuldades que o indivíduo pode ter para executar uma determinada atividade. As restrições à participação social são os problemas que um indivíduo pode enfrentar ao se envolver em situações de vida.

O reconhecimento do papel central do meio ambiente no estado funcional dos indivíduos, agindo como barreiras ou facilitadores no desempenho de suas atividades e na participação social, mudou o foco do problema da natureza biológica individual da redução ou perda de uma função e/ou estrutura do corpo para a interação entre a disfunção apresentada e o contexto ambiental onde as pessoas estão inseridas.

\section{Análise Ergonômica do Trabalho (AET)}

A Análise Ergonômica do Trabalho (GUÉRIN et al., 2001) é uma abordagem de situações de trabalho que privilegia a relação entre as condições de execução do trabalho e as atividades desenvolvidas pelos operadores, privilegiando esta última como foco central da análise. Nesta abordagem, o trabalho é analisado de forma indissociável nas suas dimensões física, cognitiva e organizacional e considerado uma atividade humana vinculada aos contextos socioeconômico e pessoal, constituída por três aspectos: a tarefa que define o trabalho a ser realizado, antecipando os resultados e determinando as condições para a sua execução, a atividade para a realização das tarefas com a utilização do corpo e da inteligência do homem e os resultados efetivos dessa atividade.

A AET possibilita a observação do trabalho real dos operadores para compreender como eles criam mecanismos intelectuais para entender os problemas a que são submetidos e quais os processos cognitivos que utilizam para a execução do trabalho (ABRAHÃO, 2000).

De acordo com Vidal (2001), a AET analisa como o operador constrói os modos de executar as tarefas determinadas pela organização do trabalho de acordo com um conjunto de características pessoais de critérios de desempenho.

Segundo Wisner (1994), a AET é feita através da observação participativa de forma sistemática das situações de trabalho, em que se procura entender como o trabalho é efetivamente realizado. Utiliza-se, para tal, análises: de demanda e propostas de contrato; dos ambientes técnico, econômico e social; e das atividades e da situação de trabalho com restituição dos resultados aos operadores.

O processo de aplicação da AET finaliza com a formulação de um diagnóstico explicativo sobre os determinantes que geraram a demanda. Este diagnóstico, após sua validação, possibilita a elaboração de recomendações para a intervenção na situação em estudo (WISNER, 1994).

Para Guérin et al. (op. Cit.), a AET utiliza a análise do trabalho real com o objetivo de compreender as estratégias utilizadas pelos operadores para realizar suas tarefas. Segundo os autores, a atividade de trabalho é um conjunto de fenômenos (fisiológicos, psicológicos, psíquicos...) que caracteriza o ser vivo cumprindo atos. Estes resultam de um movimento do conjunto do homem (corpo, pensamento, desejos, representações, história) adaptando-se a um objetivo socialmente determinado e gerando um resultado que é sempre uma “obra pessoal”, sinal de habilidade, personalidade etc. daquele que o produziu.

A Análise Ergonômica da Atividade é a análise das estratégias (regulação, antecipação etc.) usadas pelo operador para administrar a distância entre as tarefas prescritas e as atividades reais de trabalho, ou seja, a análise do sistema homem/tarefa. Nesta perspectiva, ao analisar a atividade de trabalho, é necessário procurar conhecer as diferenças entre as tarefas prescritas e as atividades reais de trabalho (GUÉRIN et al., 2001).

Segundo estes autores, sendo a tarefa um conjunto de prescrições concebidas externamente ao trabalhador e que impõem uma maneira de proceder no trabalho em um período de tempo, é admitido um distanciamento do que foi proposto pela organização e o que realmente é feito pelo operador.

O trabalho real só pode ser compreendido através da atividade de trabalho realizada pelo operador. A atividade de trabalho é uma estratégia de adaptação à situação real de trabalho, que é o objetivo da prescrição. Vidal (op. Cit.) completa afirmando que o trabalho prescrito jamais corresponde ao trabalho real, e é este distanciamento que provoca a inadequação da carga de trabalho e os constrangimentos aos operadores.

Segundo Lima (2000), a compreensão das diversidades de uma situação de trabalho indica que os trabalhadores possuem um conhecimento sobre o trabalho e que é importante, durante a análise, revelar suas estratégias e seus modos operatórios, suas competências e seus saberes tácitos, a forma de regulação das exigências contraditórias e as negociações que ocorrem no interior do processo da atividade de trabalho.

A prática da observação traz algumas controvérsias sobre "o quê" e "como" observar. A interação do pesquisador com a situação de trabalho é movida por uma demanda que parte dos atores sociais envolvidos, portanto não é uma observação neutra e ingênua. A análise e a reformulação da demanda vão orientar o aprofundamento do estudo a partir de hipóteses explicativas sobre a questão em investigação, resultando num processo de análise sistemática da atividade real. Portanto, as observações sistemáticas devem ser direcionadas para a coleta de informações com objetivos determinados, que podem envolver as seguintes categorias (GUÉRIN op. Cit.):

a) As posturas físicas assumidas pelos funcionários para a realização das atividades;

b) As ações e as tomadas de informações pelos funcionários durante a realização da atividade; 
c) Os deslocamentos dos funcionários para executar a atividade;

d) O arranjo físico do ambiente;

e) As dimensões dos postos de trabalho;

f) As habilidades sensoriais (visual e auditiva), motoras e cognitivas necessárias à realização da atividade;

Sendo a atividade de trabalho uma forma de o trabalhador alcançar os objetivos que lhe foram designados, o trabalho funciona como um elemento integrador entre fatores externos ao operador, que são os objetivos determinados pela empresa e os meios postos a sua disposição, e os fatores internos, que dizem respeito às características do organismo humano, ao conhecimento e à experiência adquiridos pelos operadores ao longo de sua história de vida, a sua personalidade e aos seus desejos pessoais.

A ergonomia, na abordagem da AET, não estabelece diferença quanto ao trabalhador apresentar incapacidade ou não, pois seu pressuposto é de que a dinâmica das condições reais de execução do trabalho é a que define a forma específica da realização da atividade. Desta forma, a ergonomia situada pode contribuir para a compreensão e a avaliação das situações de inclusão no trabalho, apontando soluções específicas para certos problemas, sejam estes de caráter fisiológico, patológico, transitório ou de diferentes tipos de dificuldades (ZURIMENDI, 1994).

\section{Modelo de reinserção baseado na ativi- dade}

O esboço do modelo apresentado a seguir é uma alternativa para as atividades de reinserção de trabalhadores em situações de trabalho após sua liberação pela perícia médica do INSS. Este modelo tem como base de análise do trabalho pela abordagem da AET (GUÉRIN, 2001) e de conceitos derivados do design participativo (DANIELLOU, 2000; GARRIGOU et al., 2002) no projeto de situações futuras, aqui considerado para situações de trabalho, que devem ser adaptadas em função de mudanças nas características psicofísicas dos novos (futuros) ocupantes.

Considera-se, nesta proposição, a existência de uma situação de incapacidade, como definida por Sperandio e Uzan (2007):

redução total ou parcial (resultante de uma deficiência) da capacidade de realizar uma atividade, de uma maneira ou dentro dos limites considerados normais para um ser humano. (p. 407)

É definida como a distância temporal, tecnológica e organizacional entre a saída do trabalhador do seu local de trabalho antes do afastamento por acidente ou doença ocupacional e seu retorno após a liberação pelo INSS. Esta situação de afastamento funcional, para efeito do modelo proposto, é tratada conceitualmente como uma situação de trabalho futura (DANIELLOU, op. Cit.) tomando como referência o trabalhador a ser reinserido.

O ponto de partida é a análise das situações potenciais de reinserção - situações de referência - sobre as quais poderão ser selecionadas situações possíveis de serem adaptadas. Esta análise se faz por um diagnóstico da atividade atual e uma prescrição, considerando, de um lado, as estratégias eficazes e seguras dos operadores atuais (estratégias de concepção) e, de outro, as estratégias ineficazes e de risco (estratégias de correção), conforme Lamonde (2007).

A escolha das situações de referência deve ser feita por profissionais de ergonomia, segurança e saúde ocupacional, considerando como critérios: a) o processo de recuperação e a funcionalidade do trabalhador a ser reinserido; b) sua ocupação antes do afastamento; c) os impactos cognitivos sobre o trabalhador em decorrência da defasagem nos processos de produção durante o período de afastamento; e d) os impactos psicológicos derivados da gravidade da lesão. Esta escolha deve considerar a análise do trabalhador em suas potencialidades, seus conhecimentos, as barreiras e os facilitadores da execução de atividades.

Esta análise permite a qualificação dos procedimentos adotados para o retorno do trabalhador pela adequação do processo de trabalho e do ambiente (espaços, artefatos, acessibilidade e relações sociais). As potencialidades do trabalhador reinserido são realizadas utilizando-se a CIF (BUCHALLA, 2001), em que são descrias a funcionalidade e a incapacidade relacionadas às condições de saúde, identificando o que uma pessoa "pode ou não pode fazer na sua vida diária”, tendo em vista as funções dos órgãos ou sistemas e estruturas do corpo, assim como as limitações de atividades e da participação social no meio ambiente onde a pessoa vive.

Associando os modelos biomédico e social a partir do referencial metodológico da CIF na abordagem da incapacidade para que haja eficácia e efetividade na reinserção, além da caracterização da capacidade e da incapacidade funcional de uma pessoa, há a necessidade de adequar as exigências do trabalho à capacidade de quem o realiza. É necessário analisar as atividades de trabalho, compreendendo adaptações dos meios físicos, seus conteúdos organizacionais e processos técnicos às pessoas, reduzindo a distância entre a incapacidade funcional e os objetivos da produção (SIMONELLI, 2009).

O conhecimento advindo da análise da atividade de trabalho na abordagem da AET permite compreender como os trabalhadores realizam suas atividades e permite explicar quais os mecanismos que o trabalhador possui para atingir seus objetivos com menor desgaste e como avaliar a carga de trabalho envolvida neste processo. Serve também de subsídio para analisar as habilidades necessárias que o trabalhador deve possuir para realizar efetivamente a tarefa prescrita. 
Esta modelagem foi proposta utilizando-se como referência as etapas básicas da AET (WISNER, 1994), adaptadas para as situações de reabilitação a partir da proposta de Simonelli e Camarotto (2008) e Simonelli (2009) para a inclusão de pessoas com deficiência no trabalho, dividida em três etapas (Figura 1):

I - Análise das tarefas e atividades

a) Estudo das tarefas nas situações de referência: posturas, movimentos, requisitos técnicos das tarefas, mudanças técnicas e organizacionais;

b) Análise das estratégias de operação: procedimentos operacionais, conhecimentos tácitos, conhecimentos contextualizados;

Esta análise, denominada de "analise das situações de referência” (DANIELLOU, 2007), pode ser adaptada para a situação de reabilitação considerando-se as possibilidades de mudanças na realização das atividades, em função das características organizacionais (divisão das tarefas, comunicação entre tarefa), sobre as características técnicas (regulagens, velocidades, sequências) e sobre os constrangimentos referenciados pelos atuais operadores das tarefas. Esta análise resulta em "situações de ação características, futuras e prováveis” (op. Cit.) como um mapeamento da variabilidade e possibi- lidades de realizar as mesmas tarefas ou alternativas de novos rearranjos das tarefas.

II - Classificação de funcionalidade e adequação do trabalho

c) Análise do trabalhador reinserido: potencialidades, barreiras e facilitadores, conhecimentos operacionais;

d) Programa de reabilitação;

e) Adequação da situação de trabalho: rearranjo do local e das tarefas com adaptações de artefatos, facilitadores para as tarefas, acessibilidade e relações sociais; em função do resultado da análise das tarefas e atividades.

III - Reinserção (projeto e avaliação da prescrição)

f) Estágio de reinserção: ocupação do posto pelo trabalhador reinserido com acompanhamento psicossocial e de desempenho técnico;

g) Avaliação das tarefas e do local pelo trabalhador e por técnicos envolvidos.

h) Geração de novos requisitos de tarefas e de novas adequações.

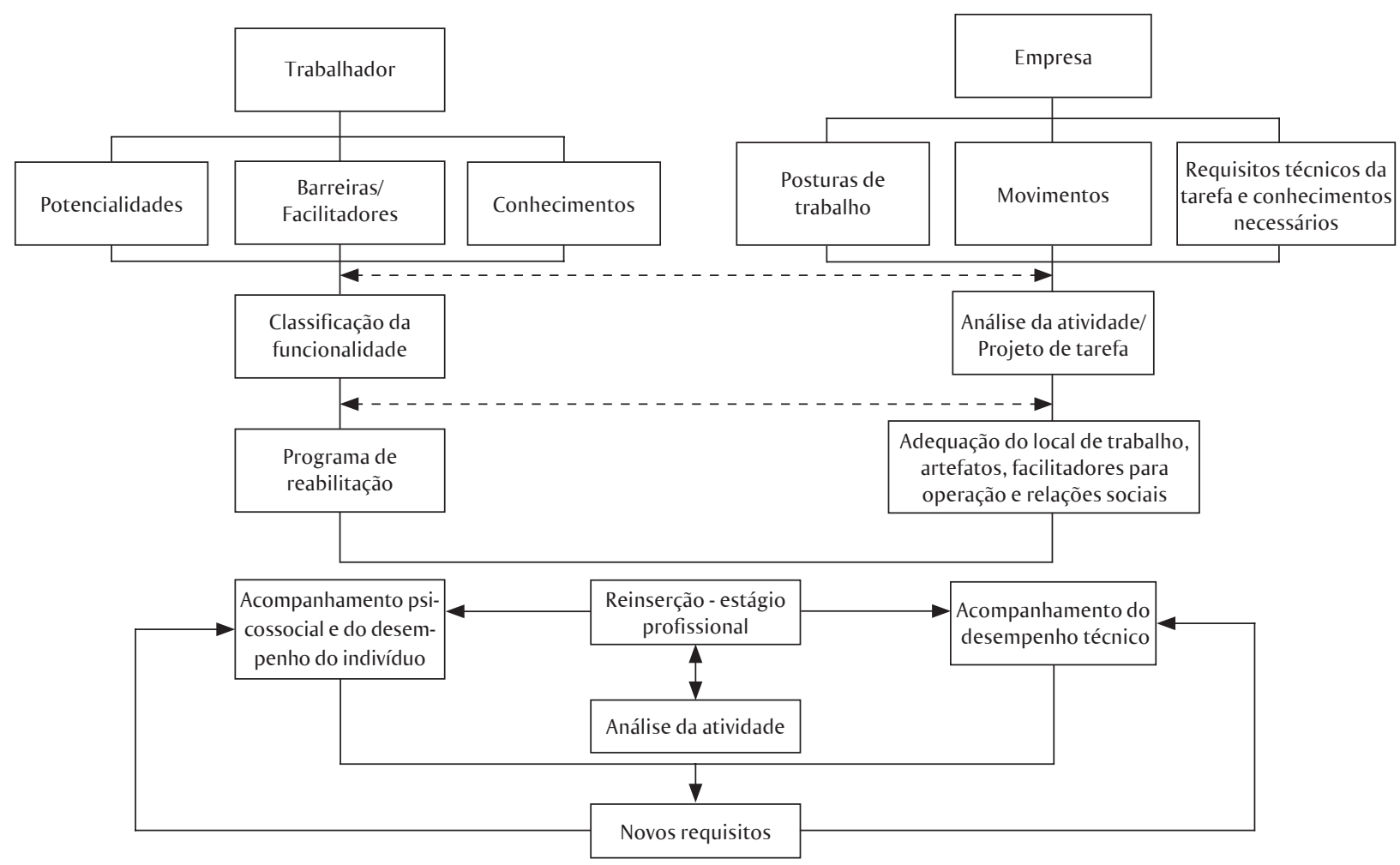

Figura 1 Proposta de modelo de reinserção no trabalho

Fonte: adaptada de Simonelli (2009) 


\section{Discussão}

O afastamento em decorrência de lesões por acidentes ou doenças ocupacionais expõe o trabalhador a constrangimentos de ordem pessoal pelas limitações físicas, decorrentes da lesão, psicológicas, pelo trauma sofrido, e de ordem social, por excluí-lo (mesmo que temporariamente) do trabalho.

Estes constrangimentos são agravados quando de seu retorno ao trabalho após o processo de reabilitação, por mudanças ocorridas no ambiente de trabalho nos processos de produção ou na organização. Assim, o deslocamento entre as expectativas do trabalhador e a nova realidade do ambiente de trabalho deverá ser tanto maior quanto for o tempo de afastamento. Neste sentido, a reinserção necessita considerar formas de diminuir este descolamento.

Não se pode considerar o processo de reabilitação desvinculado do processo de reinserção, como não se pode deixar de considerar a análise da atividade de trabalho para a adequação do local de trabalho ao trabalhador reinserido. O foco da análise da atividade está na observação em situação real e na forte interação com o trabalhador. Segundo Guérin et al. (2001), a análise da atividade incide sobre um trabalho efetivamente realizado, enquanto que as outras abordagens se apoiam em representações artificiais deste trabalho, portanto, fora da realidade efetiva da realização do trabalho.

Considerar o trabalhador como sujeito ativo e transformador da realidade do trabalho é uma ação social e uma forma econômica de garantir o sucesso da reinserção no trabalho. É necessário também considerar que o processo de reinserção (e de reabilitação) não pode ser

\section{Referências}

ABRAHÃO, J. I. Reestruturação produtiva e variabilidade do trabalho: uma abordagem da ergonomia. Psicologia: Teoria e Pesquisa, v. 16, n. 1, p. 49-54, 2000.

BUCHALLA, C. M. (Org.). CIF - Classificação Internacional de Funcionalidade, Incapacidade e Saúde. São Paulo: Universidade de São Paulo, 2001.

BRASIL. Portaria Interministerial MPS/MS/MTE № 800, de 03 de maio de 2005 - DOU de 05/05/2005. Política Nacional de Segurança e Saúde no Trabalho. Diário Ofical [da] União, Poder Executivo, Brasília, DF, 05 maio 2005. Disponível em: <http://www. previdenciasocial.gov.br/>. Acesso em: 17 fev. 2009.

DANIELLOU, F. Análise da atividade futura e a concepção de instalações externas. In: DUARTE, F. (Org.). Ergonomia e projeto na indústria de processo contínuo. Rio de Janeiro: Lucerna, 2000. p. 75-83.

. A ergonomia na condução de projetos de concepção de sistemas de trabalho. In: FALZON, P. considerado como uma responsabilidade ou insuficiência do trabalhador.

O acidente e a doença ocupacionais são fenômenos indesejáveis gerados por e nos ambientes de trabalho como resultado de uma desestruturação entre o projeto das situações de trabalho e as condições concretas de sua realização. Portanto, os efeitos dos acidentes e das doenças ocupacionais devem ser equacionados no âmbito do contexto deste trabalho.

A reabilitação profissional, ao se apoiar na AET, incide sobre os determinantes do desequilíbrio entre o processo de trabalho e o ser humano e pode auxiliar no surgimento da dimensão preventiva, de modo que um trabalho patogênico, que adoeceu ou acidentou pessoas, seja corrigido, eliminado.

Como não existem ilhas isoladas dentro de sistemas complexos interligados, ao tornar saudável uma situação de trabalho, a reabilitação profissional pode auxiliar na adoção de uma atitude preventiva dentro da organização, despertando um olhar crítico sobre outros processos e situações que ainda apresentem potencial de risco à saúde.

O processo de reinserção do trabalhador reabilitado apresenta uma dificuldade maior se comparado com o início de trabalho de um trabalhador novato (ou de mudança de emprego) em uma nova situação, pois o trabalhador reabilitado traz consigo os reflexos negativos de situações anteriores que determinaram seu afastamento e consequente redução (temporária ou permanente) de sua capacidade laboral. Este modelo, embora trate particularmente desta situação, ainda necessita de uma reflexão prática que lhe permita avançar na compreensão dos processos psíquicos e sociais desta relação.

(Ed.). Ergonomia. São Paulo: Edgard Blücher, 2007. p. 303-316.

GARRIGOU, A. et al. A análise de atividades no âmbito intrínseco e extrínseco do design participativo. CITEC. Separata, 2002.

GUÉRIN, F. et al. Compreender o trabalho para transformá-lo: a prática da ergonomia. 2. ed. São Paulo: Edgard Blücher, 2001.

LAMONDE, F. As prescrições dos ergonomistas. In: FALZON, P. (Ed.). Ergonomia. São Paulo: Edgard Blücher, 2007. p. 331-342.

LIMA, F. P. A. Ergonomia e projeto organizacional: a perspectiva do trabalho. Revista Produção, n. Especial, p. 71-98, 2000.

OLIVER, M. The politics of disablement. London: MacMillan, 1990.

. Theories in health care and research: theories of disability in health practice and research. British Medical Journal, v. 317, n. 7170, p. 1446-1449, 1998. 
ORGANIZAÇÃO MUNDIAL DE SAÚDE. Rumo a uma linguagem comum para funcionalidade, incapacidade e saúde: CIF. Genebra: OMS, 2002.

SIMONELLI, A. P. Contribuições da análise da atividade e do modelo social para a inclusão no trabalho de pessoas com deficiência. 2009. 221 f. Tese (Doutorado em Engenharia de Produção)Departamento de Engenharia de Produção - TTO - Trabalho, Tecnologia e Organização, Universidade Federal de São Carlos, São Carlos, 2009.

SIMONELLI, A. P.; CAMAROTTO, J. A. Industrial task analysis aproach as a tool for inclusion of peoples whit special needs in the work market. Occupational Therapy International, v. 15, p. 150-164, 2008.

SPERANDIO, J.; UZAN, G. Ergonomia dos suportes técnicos informáticos para pessoas com necessidades especiais. In: FALZON, P. (Ed.). Ergonomia. São Paulo: Edgard Blücher, 2007. p. 407-422.

TAKAHASHI, M. A. C. Incapacidade e previdência social: trajetória de incapacitação de trabalhadores adoecidos por LER/DORT no contexto da reforma previdenciária brasileira da década de 1990. 2006.
332 f. Tese (Doutorado)-Univesidade Estadual de Campinas, Campinas, 2006.

TREZUB, C. J. Perícia médica: conceitos e fundamentos. Sociedade Brasileira de Perícias Médicas, 2006. Disponível em: <http://proweb. procempa.com.br/pmpa/prefpoa/previmpa/usu_doc/ microsoft_powerpoint_-_claudio_trezub_2_ \%5Bsomente_leitura\%5‥pdf $>$. $\overline{\text { Acesso em: }} 18$ maio 2009.

VERBRUGGE, L. M.; JETTE, A. M. The disablement process. Social Science Medicine, v. 38, n. 1, p. 1-14, 1994.

VIDAL, M. C. R. Ergonomia na empresa: útil, prática e aplicada. Rio de Janeiro: Virtual Científica, 2001.

WISNER, A. A metodologia na ergonomia: ontem e hoje. In: A inteligência no trabalho: textos selecionados de ergonomia. São Paulo: Fundacentro, 1994. p. 87-107.

ZURIMENDI, M. M. Conceptos de ergonomia: critérios para la adaptacíon persona - puesto. In: FUNDACÍON MAPFRE MEDICINA. Metodologias y estratégias para la integracíon laboral. Madrid: Mapfre, 1994. p. 92-99. 